\title{
The Way to Enhance the Competitive Power of Tourism Industry Under the Background of the "Belt and Road" in Qingyang
}

\author{
Fei Wang ${ }^{1}$, Jinghua Zhang ${ }^{2}$ \\ ${ }^{1}$ College of History and Geography, Longdong University, Qingyang, Gansu, 745000, P.R. China \\ ${ }^{2}$ College of Economics and Management, Longdong University, Qingyang, Gansu, 745000, P.R. China
}

Keywords: Qingyang, competitiveness, tourism industry, the Belt and Road Initiative

\begin{abstract}
The Silk Road along the city of Qingyang, a major channel of international political and economic integration of communication, seizes the historical opportunity to actively integrate "the Belt and Road "Initiative, deepens the culture mining, improves the quality of tourism products, around five major tourism brand building, enhances the overall competitiveness of the tourism industry.
\end{abstract}

\section{Introduction}

Qingyang takes the construction of " One Belt and One Road " as an opportunity to speed up the construction of the most well - known tourist destination and the gathering, construction of the most well - being cities as the target, and insists on the government - led, corporate follow - up and social - boosting three - wheel drive, and actively constructs the Great Tourism Circle of Xi ' an and Bao chickens, Pingliang and the adjacent areas of the western region. The promotion path of the competitiveness of tourism industry in Qingyang will help to promote the development of the tourism industry in Qingyang and enhance the overall competitiveness of the regional economy. The paper intends to carry out the path research to enhance the overall competitiveness of Qingyang tourism industry.

\section{Shaping a Distinct City Image and Raising the City's Popularity}

\subsection{Make Full Use of the Advantages of Existing Resources to Display the Urban Scenery on the Loess Plateau}

The first Paleolithic in China, "the Yellow River ancient elephant" fossils and "Huanjiang pterosaur" fossils were unearthed in Qingyang. Qingyang is the birthplace of the Chinese nation and one of the birthplaces of the Yellow River civilization. Qingyang is the source of Qihuang traditional Chinese medicine culture. Folk culture is unique, fragrant bag, long embroidery, and folk paper-cut. Taoism shadow and Longdong folk songs are called Qingyang "five absolute"; To reform the current tourism management mechanism, to strengthen the main body of the tourism market, improve the quality of tourism services, broaden the channels of tourism investment and financing, south of Lianghong tourism scenic spots, Zhou Zuling, Tianfu billion and other high-quality scenic spots as the engine. We will promote the construction of key scenic spots and health resorts, expand the level and space of tourism products, and focus on the transformation of tourism products from traditional tours to sightseeing, leisure and vacation. Shows loess scenery; enhances the overall competitiveness of the tourism industry in Qingyang.

\subsection{Pay Attention to Urban Public Space Design and Create Famous Urban Landscape Urban Public Space is the Charm of the City, and so is the Soul of the City}

The well-known landscape is an effective means to enhance the visibility of the city. Qingyang is also an important factor to reflect the image of the city. In order to build a famous and even international plateau red tourism city, Qingyang has strategic thinking in urban planning. While strengthening the layout of urban plane planning, it is necessary to rationally layout the green space 
system parks and urban space structure, optimize the central square of the city, highlight the regional characteristics of the old districts, construct the urban landscape and plan the green space. Leisure facilities design layout, urban landmark planning and other elements reasonable collocation, synchronous construction, especially in the urban landscape elements layout should highlight the natural and social attributes of the Red City on the Loess Plateau. It is also necessary to show the characteristics of plateau geography and loess culture through landscape shaping.

\subsection{Adopt Diversified Propaganda Mode to Improve the Validity of Image Communication the Communication of City Image is a comprehensive Project}

The effective way of city image communication should be the combination of traditional media and new media. There are many ways of word of mouth publicity, city image advertising, film and television communication, government public relations, festival communication and other means of communication of urban image to comprehensive dissemination and construction. At present, Qingyang image communication mode is relatively single, mainly festival communication, some agricultural culture and folklore festival. Film and television communication can achieve the best result with half the effort, but Qingyang lack of film and television communication media at present. Therefore, Qingyang should fully explore the cultural connotation. Actively seek various forms of film and television cooperation, seize all the opportunities to show the image of Qingyang, or increase investment to invite famous film director, film and television script, invited well-known directors and famous actors to participate. Try to broadcast in CCTV, in order to achieve a high coverage of the film and television image of the city, vivid image of the communication effect, for the development of tourism industry laid a long-term foundation.

\section{Deep Development of Tourism products and creation of famous Tourism Brand}

\subsection{Expand the Product Types and Establish a Diversified Product System}

At present, Qingyang tourism industry related product design and development type is single, there is a strong alternative. Qingyang tourism industry focuses on the construction of sightseeing mainly, and supplemented by cultural tourism, adventure tourism, entertainment tourism, sports tourism, Folklore tour, education tour. A diversified system of tourism products, such as vacation and conference tours. It is an alternative and feasible way to correctly transform and upgrade the existing tourism products in Qingyang: First of all, the traditional tourism products are optimized and upgraded. Tourism products are the basic level of tourism activities. Qingyang is unique geological topography in the Loess Plateau. As a newly developed Loess Plateau city, Qingyang has a fast pace of urban infrastructure construction and a rapidly changing city appearance. The city is expanding rapidly and the streets are clean and wide. Qingyang tourism industry can consider increasing the city landscape tourism products. In the future, urban construction planning should focus on highlighting the urban characteristics of the Loess Plateau. Secondly, it is necessary to strengthen the development of new tourism products. It is difficult to meet the needs of tourists and the requirements of in-depth experience. Tourism experience project has a strong participation and entertainment, and has a strong word-of-mouth transmission effect. Finally, in the process of tourism product development, Qingyang should strengthen the strategy of "promoting tourism through science and technology" and carry out scientific and technological cooperation with domestic and foreign tourism. Increasing the investment of tourism science and technology and enhancing the level of science and technology of tourism products make science and technology become an effective means to promote the sustainable development of tourism in Qingyang.

\subsection{Excavating Local Characteristics and Increasing the Cultural Connotation of Products}

Tourism is on the surface a tourist activity of a tourist destination, essentially a deep demand behavior activity for cultural experience. Specifically, tourism activity is a natural tourism resource, a historical and cultural resource, and a tourism management culture. The effective integration of tourism consumption culture and other aspects not only has a strong economic cultural cause, but 
also has a strong cultural attribute, although tourists have different levels and different identities. They have different starting points and different demands for highland urban tourism products, but with the development of economy and society and tourists themselves, they are becoming more and more mature. The common demand for cultural identity will be higher and higher. To meet the needs of all types of tourists at all levels. Qingyang should deeply excavate and develop tourism products on the basis of highlighting the natural attributes of loess plateau and the social attributes of red cities, so that the attributes of "loess" and "red" can be deeply integrated into tourism products. Tourism cultural products, such as loess style, red revolutionary history, plateau unique architecture and local food and drink, which can fully display Qingyang's unique charm, will be introduced to tourists.

\subsection{Improve the Quality of Products and Strengthen the Construction of Tourism Brands}

Tourism brand is a symbol is a model is representative. Tourism brand, especially the design and development of tourism boutique projects can provide tourists with more colorful feeling of demand, and effectively increase the stay time of tourists. Increase tourism-related consumption. Qingyang tourism brand is not strong; in the tourism market is not high. In addition to increasing publicity, Qingyang also develop tourism products in the construction of brand engineering. In order to achieve sustainable development, we should pay attention to the cultivation of Qingyang tourism brand, focus on leading efforts to create and launch some brand tourism products, and promote the Qingyang tourism market from the low-end to the high-end transformation. Promote the whole Qingyang tourism industry optimization and upgrading.

\section{Improve related facilities and improve the overall quality of tourism environment}

\subsection{Improve the Urban Transportation System and Improve the Urban Accessibility}

Tourism channel construction is between tourists and tourism destination is key factors of smooth access. Qingyang traffic network developed rapidly in recent years. At present, Bank of the West high speed railway construction, then Qingyang will become an important hub of Gansu railway, will lead the Qingyang entered the era of high-speed rail, and the formation of Guanzhong City Group, city belt along the Yellow River more closely contact network quickly. Air is the most convenient mode of transportation, is the first choice for long distance travel. Although the Qingyan Airport extension is put into use, but a single line, fewer trips. Qingyang is to build a national and even international tourist city, to expand its own airport, increase air traffic and build a three-dimensional traffic network.

\subsection{Strengthen Brand Hotel Cultivation to Improve the Hospitality and Service Level of Tourist Accommodation}

High quality hotel is mainly reflected in the infrastructure and service quality, is an important measure of a city's soft power, reflecting the city's tourism quality. Qingyang will play a well-known plateau tourist city, vigorously cultivate the star hotel is one of the path to improve the quality of tourism. Tourism Management Department of Qingyang to guide the existing hotel the establishment of Star Association or group, unified deployment of industry association to study the implementation of five-star standard, star hotel standard hotel industry staff. At the same time, in accordance with the construction of five-star standard of infrastructure of the hotel, with modern technology into the hotel's fast pace, including the use of artificial intelligence, such as intelligent temperature control, intelligent light control, broadband the Internet, wireless coverage, satellite network coverage, to provide a new service of global information high-speed service to tourists. The innovation of hotel management mode, the introduction of well-known hotel the management group encourages local brand hotels to collectivize construction. Under the goal of "environmental protection, green, safety, health and energy save", the management level of Qingyang hotels has been greatly improved. 


\section{Strengthening Regional Cooperation and realizing Tourism Integration}

\subsection{Integrate Tourism Resources and Strengthen Joint Development in the Region}

Qingyang, relatively scattered spatial distribution of resources, the territory of all the counties, grotto resources is very concentrated, red culture tourism resources are relatively concentrated in Huachi County South beam, but also scattered. The overall tourism resources in Qingyang showed a "small gathering, massive distribution situation of large and scattered" pattern. From the tourism theory, tourism resources the zonal distribution of tourist tourism can increase the retention time, tourism benefit is more obvious, integrate surrounding tourism resources based tourism in Qingyang in a small to gather on the formation of ribbon development situation, the tourism management department said difficult to integrate the overall design. The massive distribution of tourism resources is relatively easy, Qingyang open up tourism channel in the tourism resources based on the dispersion pattern, construction of infrastructure, suitable for large-scale development.

\subsection{Create a Tourist Environment and Strengthen Cooperation with Other Cities}

In the social division of labor is increasingly refined today, cooperation is both productive and cooperation benefits. Tourism development cooperation also results. Tourism cooperation aimed at different city tourism resources complementary, synergies, enhance the competition. The tourism industry in Qingyang, in addition to the integration of tourism management department to strengthen the resources within the region, but also to strengthen the city and tourism the surrounding, especially tourism cooperation in the city such as Yinchuan, Xi'an. The Qingyang Municipal Tourism Bureau and the Shaanxi city of Yanan Province Tourism Bureau in a resource sharing, information exchange, product pushing, cooperation and "win-win" principle, in consultation with the formation of Yanan - Qingyang red tourism regional cooperation declaration form the following Declaration: regional cooperation. (1) Protect red tourism resources together. Red tourism resources are non renewable precious collaboration, the parties should take joint measures to protect, and strive to achieve the Red Brigades sustainable development of tourism. (2) Create red tourism routes together. All cooperation of red tourism resources are rich, monopoly, in the preparation of local red tourism routes, we should follow the principle of "concentric, interactive, win-win" business philosophy, the other tourism products included in the line of travel, improve the regional joint. (3)Co-cultivate red tourism brand marketing. Strengthen the red tourism, red tourism product integration planning and packaging publicity and cooperation of the parties, to foster the development of red tourism brand. (4) Jointly open up the tourism market. Cooperative parties should open the tourism market, build a barrier free Tourism Zone actively, and jointly create a safe, civilized, honest, harmonious tourism scenic spots the environment. (5) Establish long-term cooperation mechanism. Cooperation parties should establish information sharing, personnel training, tourism enterprises, tourism quality complaints, a major security management mechanism, and to determine the associated Contacts with all parties, visits to the other cities, exchanges, participation in major festivals and red tourism seminars, and facilities.

With the continuous development of tourism economy growth, the competition between the regional tourism industries has become increasingly fierce. Qingyang as the old revolutionary base areas don't often emphasize red historical and cultural resources, should seek the innovation of tourism development path, specific to expand tourism investment, create new tourism development ideas, strengthen the tourism information communication, training and retaining tourism management talents strategy in particular to the tourism industry policy and construction of tourism enterprises and tourism macro management measures such as to truly rely on advanced tourism production factors, the formation of "government leading, enterprise autonomy, self-discipline, coordination between departments, social participation" tourism pattern, and continuously improve the Qingyang Tourism in Gansu, Northwest China even China tourism market competition status, so as to improve the overall competitiveness of the tourism industry in Qingyang. 


\section{Acknowledgements}

The paper is the annual strategic research project of colleges and universities in Gansu: the periodical result of the way to improve the overall competitiveness tourism industry under the "One Belt and One Road "strategy in Qingyang (Project No. 2017F - 27).

\section{References}

[1] Pang Weihua. A study on the development of red tourism resources: a case study of Liangdang County, Gansu Province [J]. Journal of Gansu normal University. 2013, (4):130.

[2] Yin Xiaoying, Zhu Hong. Study on the characteristics and development model of red tourism products [J]. Humanities Geography. 2005, (02):34.

[3] He Chao, Song Yongyong, Xue Fang. SWOT Analysis of Red Tourism in Qingyang [J]. Journal of Longdong University. 2013, (04):95.

[4] Ma Jinfu, Song Zhenmei. A brief Analysis of the Characteristics and Development Strategies of Red Tourism Resources [J]. Journal of Beijing second Foreign Language University. 2006, (1):111-114.

[5] Liu Hai, Ming Jing. Red Tourism: concept, Development course and Development Model [J]. Hunan Business School (bimonthly). 2010, (1):69.

[6] Yuan ping. A brief analysis of the development of red tourism resources in Henan [J]. Journal of Kaifeng University. 2006, 20(3):27.

[7] Wang Weinian, Rong Yuxin, Bai Zhulan. Study on Regional Culture and Red Tourism Development [J]. Enterprise economy 2007, (5):142-145. 